\title{
Ética e Subjetividade: indagações em Habermas e Rorty
}

\author{
Leônia Cavalcante Teixeira \\ Universidade de Fortaleza
}

\begin{abstract}
Resumo
Considerando que o momento civilizatório atual se define como de crise epistêmica, antropológica, ontológica e ética, este breve escrito aborda, a partir da consideração da tradição iluminista, as concepções de dois pensadores emblemáticos da contemporaneidade: Jürgen Habermas e Richard Rorty. Habermas parte de uma feroz crítica ao unilitarismo em que o ideário da Ilustração desembocou, questionando o tecnicismo e optando pelo repensar o homem e o mundo através da retomada de uma ética iluminista cosmopolita emancipatória. Baseando-se na tradição linguístico-pragmática, Rorty posiciona-se vigorosamente contra as perspectivas iluministas antropológica, epistêmica e ética. O autor afirma que o cosmopolitismo pela solidariedade comunicacional deve ser alvo de nossas lutas, porém sem o norte da emancipação, que perde seu sentido com a derrocada das categorias de substância, essência, verdade, razão... A discussão entre os autores dar-se-á considerando as relações entre ética e subjetividade.
\end{abstract}

Palavras-chave: modernidade; ética; subjetividade; Habermas; Rorty.

\begin{abstract}
Ethics and subjectivity: investigations in Habermas and Rorty. Considering that the current civilizatory moment is defined by the epistemic, anthropological, ontological and ethical crises, this short paper deals with the concepts of two emblematic thinkers of contemporaneity, from the consideration of the illuminist tradition; those thinkers being: Jurgen Habermas and Richard Rorty. Habermas starts with fierce criticism of unilateralism in which the set of ideas of the Illustration ends up questioning the technicalness of it and opting for rethinking man and the world through taking up, once again the emancipating, cosmopolitan, illuminist ethic. Based on the linguistic-pragmatic tradition, Rorty, vigorously positions himself against the anthropological, epistemic and ethical illuminist perspectives. The author affirms that cosmopolitism through communicational solidarity should be the aim of our struggles, however without the direction of emancipation, which loses its meaning with the overthrow of the categories of substance, essence, truth, reason... The discussion between the authors takes into consideration the relationships between ethics and subjectivity.
\end{abstract}

Key words: modernity; ethics; subjectivity; Habermas; Rorty.

Ilustração e Iluminismo: pressupostos antropológicos, epistêmico-metodológicos e éticos da modernidade

Ilustração consistiu em um movimento cultural-filo-
sófico que trouxe novos ares à Europa do final do
século XVII e, principalmente, do século XVIII. A Filosofia das Luzes tinha características bem próprias, dentre elas a afirmação do homem e a confiança na razão. O homem passa a ser visto como centro do mundo e manipulador da natureza. A razão é entendida como instrumento de ação e não mais de contemplação. O homem pode conhecer o real, não havendo mais campos privilegiados dos quais a crítica racional deva ser excluída, sendo estendida aos poderes cognoscitivos humanos, a toda e qualquer crença e conheci- mento. A razão passa a ser o guia em todos os campos da experiência humana e, com isso, a Ciência assume lugar de importância, bem como a História e, conseqüentemente, a idéia de perfectibilidade inclusa na perspectiva do progresso.

Aliás, a confiança na razão e no progresso são marcas registradas do pensamento iluminista. O homem desafia a tradição e a autoridade, sendo incentivado a pensar livremente. Essa ruptura com o modelo cosmocêntrico é responsável pela abertura à consciência, possibilitando uma visão progressista, segundo a qual existe a possibilidade da construção de um mundo melhor.

O indivíduo é remetido a si mesmo, pois, com a proliferação de diferenças e de contraposições ao modo de subjetivação medieval, principalmente pelo Renascimento, a religião não possibilita mais os recursos razoáveis para o 
homem dar conta de si, não oferecendo mais um modelo forte o suficiente em torno do qual as subjetividades possam se estruturar. O indivíduo, então, recorre a si mesmo para organizar suas experiências, colocando-se como fundamento autofundante, sendo a base de suas crenças pelo assumir-se como sujeito epistêmico e, também, como sujeito da ética, da moral e da política. Tal processo de autofundação exige um posicionamento diverso em relação a si e aos outros, já que, pela ênfase nas experiências subjetivas, torna-se necessária uma cisão entre o que pode ser compartilhado livremente com os demais, por enquadrar-se, sem dificuldade, no território mediado pela razão e o que não é compartilhável com os outros e, provavelmente, não seguro para si mesmo, por estar em um território de experiências subjetivas não confiáveis, sem submeter-se às censuras racionais, sendo, então, experienciadas com estranheza: o mundo de experiências da vida pública e da vida privada. Nesse sentido, o sujeito, ao tornar-se o fundamento, paga o preço de ter que administrar suas vivências subjetivas a partir do crivo racional que, como seu guia, impõe-lhe espaços nos quais deve experienciar-se distintamente.

A distância, acentuada cada vez mais no decorrer da efetivação da modernidade, com o campo de conhecimento ordinário legitimado pelos mitos nas sociedades tradicionais, é bem discutida por Lyotard (1985), que considera tanto o colapso das metanarrativas como uma das mais fortes conseqüências da modernidade, como exprime a crença de que, embora o discurso científico aspire ao projeto de realização da universalidade, termina por acelerar sua deslegitimação. A Ciência, sempre em confronto com a legitimação aos saberes populares, cotidianos e míticos das narrativas, passa a reduzir a variedade e o pluralismo de experiências por elas perpassados para um modo hegemônico de legitimação, fundamentalmente epistêmico e sociopolítico, consolidado pelo racionalismo conceitual.

O direito ao uso pleno da razão como meio de liberdade, de autonomia intelectual, também se reflete no direito de participação democrática de cidadania e no direito de usufruir dos bens e serviços que promovam a satisfação individual, isto é, no direito e na capacidade de obter autonomia política e econômica.

Outro ponto enfatizado é a idéia de uma natureza humana universal, conferindo substância à tese de que todos os homens são iguais, independentemente de sexo, raça, nacionalidade, classe e religião. A Ilustração é igualitária em sua concepção sobre o homem: às diferenças e às peculiaridades, a unidade da espécie é que se sobrepõe. Diversidades de locais de origem, de culturas, de sexos e de raças não justificam as argumentações de que o homem é múltiplo e de que, portanto, as diferenças o caracterizam. As particularidades existem, porém são secundarizadas pelo fato de que só emergem a partir da tese fundamental da existência de princípios básicos da natureza humana. A ênfase nas particularidades não coincide com os pressupostos da Ilustração e, portanto, não fazem parte do corolário iluminista.

O século XVIII se firmou pela crença no cosmopolitismo, daí a premissa ilustrada de que todos os homens são cida- dãos do mundo inteiro, sendo o universo, como um todo, a pátria de todo homem. Apesar do conhecimento das particularidades históricas, geográficas e, principalmente, culturais, a Ilustração era universalista, concebendo a ênfase nessas particularidades como etnocentrismos, opondo-se radicalmente, a quaisquer justificativas que afetassem o postulado de homem genérico, universal. Como seres racionais, as diferenças não podem ser tomadas como motivos para discriminação, supressão de direitos, prestígio e autoridade.

A concepção de que todos são responsáveis pelos seus atos também é outro argumento das Luzes, já que, como ser racional, o homem é autônomo. Ele é considerado diferente da sua comunidade de origem, passando a ser visto como capaz, portanto, de se distanciar, descentrar-se de seu locus. O homem pode ficar em uma posição de exterioridade em relação a sua sociedade, colocando-se em uma perspectiva em que há possibilidade de fazer julgamentos: olhar, avaliar, ponderar e questionar. O homem não fica mais preso às circunstâncias do seu nascimento: a natalidade não é mais uma fatalidade. Através da descentração, que lhe é agora possível pela sua individualidade, o homem permite-se uma visão crítica da realidade, das instituições sociais. Sua razão, agora, é seu guia. A identidade do homem é construída por ele próprio e isso lhe é possível em razão das possibilidades de descentração de seus ambientes, podendo julgá-los e não ser determinados por eles. Enfim, o homem passa a se guiar pela possibilidade de crítica.

A relação sujeito-objeto serve de modelo ao paradigma, pois evidencia o caráter anônimo do conhecimento científico, que tanto se constrói como alienado da pessoa do criador na busca frenética pelo maior nível de objetivação possível, tanto como ato de conhecer por leis gerais e universais que, como categorias de inteligibilidade, atravessam a aparência de singularidade dos fenômenos. Rompe, portanto, com o conhecimento ordinário pela desconsideração da interação do sujeito de conhecimento e da finalidade das coisas: tudo está em torno da previsão e do controle, do utilitarismo e da funcionalidade em um mundo mecanicista bem-estruturado. $\mathrm{O}$ rigor científico do conhecer, eqüivalendo ao quantificar, sustenta-se no instrumento privilegiado de análise do modelo matemático, cuja lógica de investigação supõe uma redução radical da complexidade do real, apreensível em sua fragmentação, pelo conhecimento objetivo e fatual do homem como sujeito epistêmico universal. Nesse sentido, pela idéia de progresso, o mundo é sempre passível de ser mais bem descoberto por leis, inclusive os fenômenos psicológicos e sociais dimensionados em seus aspectos externos, observáveis e mensuráveis, apreensíveis pelos mesmos princípios epistemológicos e metodológicos de estudo da natureza.

Assim, o ideário moderno propunha, antes de mais nada, a emancipação do homem pela razão, bem evidenciada pela filosofia da subjetividade instaurada predominantemente por Kant, responsável principal pela inserção do homem na maioridade, sem amarras que limitem o uso pleno da razão, como fonte articuladora de sentido do mundo lógico-matemático e do mundo prático das relações. Rouanet (1993, p. 46) analisa 
a filosofia da ilustração a partir do cognitivismo, do universalismo e do individualismo, sintetizando, através desses três pontos denotativos das teorias morais do século XIII, as idéias supracitadas.

A partir da exploração dos solos antropológico e epistemológico modernos, conclui-se que o projeto proposto na Ilustração já se instaurou, mesmo como ideário, portando o germe de sua falência posterior, já que, desde lá, as perspectivas ética e técnica eram concebidas separadamente, ambas a partir do exercício da razão, porém não efetiváveis como vieses de um mesmo movimento de crítica, tal qual as denominações e campos kantianos da razão crítica e da razão prática. Tais germes, postos nas promessas emancipatórias iluministas, não podem ser negligenciados quando a ênfase recai na análise dos processos de subjetivação, já que toda produção de subjetividade moderna é forjada tanto por essas promessas sedutoras totalizantes de libertação humana e bemestar social, como pelas conseqüências de seus não êxitos.

As luzes do século XVIII não nos possibilitam mais apreender o real, nem este se põe mais à apreensão como antes. Melhor escrevendo: a complexidade do real ofusca a luz que a idéia iluminista de razão nos possibilita ver.

\section{Sobre a retomada iluminista de uma ética racional}

A crise, há pouco referida, questiona tal hegemonia "representacional” que caracteriza os espaços teórico e prático do esquema moderno. É interessante ressaltar que as críticas dos iluministas contemporâneos, em sua maioria, recaem sobre o desvario que o saber instrumental produziu no campo da qualidade de vida - incrementada em seu ar tecnológico potencial, porém diminuída em seu aspecto interrelacional, propondo a revisão da idéia moderna de razão.

Habermas (1989), com a Teoria da Ação Comunicativa, reformula a noção de razão, chamando-a razão comunicativa que, no interior da Ética Discursiva, constitui a proposta de maior força de tornar contemporâneo o projeto iluminista. Assim, ele diverge da conotação pessimista que caracterizava as produções da Escola de Frankfurt, pois estas sempre apontavam, com bastante descrédito, para os problemas ensejados pela instrumentalização exagerada de que se revestiu a racionalidade. Rouanet $(1987,1993)$ assume o propósito de realizar uma discussão crítica, em interlocução com a Psicanálise, sobre as contribuições teóricas da Escola de Frankfurt, sendo um dos responsáveis por sua disseminação no Brasil e, junto a Freitag $(1990,1992)$, das teses habermasianas.

Habermas (1989), a partir do trabalho com base interdisciplinar, defende ferozmente a parceria entre investigação filosófica e pesquisa empírica - Ciências Sociais e Humanas, tendo se apoiado em Piaget e, principalmente, em Kohlberg para defender com maior legitimidade seu projeto de revigoramento da razão, ou melhor, de sua possibilidade argumentativa, com caráter eminentemente emancipatório, substituindo os ditames da razão instrumental: da razão centrada no sujeito para a razão “comunicacional”.

Toda constituição conceitual habermasiana baseia-se na proposta de uma razão fundamentada na comunicação, na argumentação, no discurso, no entendimento entre sujeitos capazes de falar e agir. A linguagem deixa de possuir uso puramente cognitivo e de ser abordada apenas como tal, sendo a orientação consensual que deve nortear a interação dos sujeitos: o paradigma do conhecimento de objetos - Filosofia da consciência de si, da auto-referência que marca o conhecer e o agir, é substituído pelo paradigma da compreensão mútua.

A ética baseada no discurso é pensada a partir da subjetividade dos participantes, extravasadas, continuadamente, nas possibilidades de comunicação como mediadoras e doadoras de sentido às relações entre aos atores de uma comunidade lingüística. O "mundo-da-vida” abarca toda tradição cultural: as instituições, as estruturas cognitivas e afetivas, os atos-de-fala, as teorizações, os bens documentais, isto é, tanto a objetivação das expressões humanas como e, prioritariamente, a subjetividade dos atores, sempre sujeitos sociais - os processos da socialização guiam a participação dos sujeitos na situação de comunicação, já que a ação comunicativa é o meio pelo qual o "mundo-da-vida” se reproduz.

A modernidade, com a ênfase na razão, possibilitou a evidência dessa competência lingüística, ao mesmo tempo que a sufoca com a força aniqüiladora do racionalismo. Assim, a Teoria da Ação Comunicativa, situada no campo da Ética Discursiva, em última análise, busca revitalizar a potência do "mundo-de-vida”, pretendendo situar a razão comunicativa como eixo de todo o processo civilizatório: razão comunicativa como recontextualização da razão iluminista.

Apel (1994, p. 173), seguindo tal tradição iluminista, defende uma ética que tenha fundamentos racionais universalistas, contrapondo-se às posições relativistas tão em voga atualmente. Ele sugere uma “macro-ética”, que corresponderia ao nível mais elaborado da civilização, abarcando a noção de homem universal, cuja reflexão ética atinge a humanidade como um todo, buscando sua autopreservação e, como não poderia deixar de ser, a preservação do planeta. Para que essa perspectiva globalizante seja alcançada, a civilização precisa atravessar dois patamares: a "micro” e a "meso" éticas. A primeira corresponde às relações da esfera privada, como família, clã e grupo, com linguagens e preocupações limitadas aos seus participantes. Já a meso-ética, como nível intermediário, vislumbra um horizonte mais amplo, embora ainda circunscrito à Polis, ao Estado. A perspectiva que conseguiria se firmar como contraproposta às posições radicais do relativismo cultural, racial, geográfico e econômico, segundo Apel, seria a de uma ética universalista, apoiada na responsabilidade compartilhada por todos, indistintamente de suas características peculiares, mas baseada no irredutível que marca o humano: faz-se necessária e urgente uma visão planetária da ética, e não mais a "privatização" a que a ética vem se submetendo, dizendo respeito somente às decisões de caráter individual.

O projeto ético sustentado pela possibilidade da razão como guia privilegiado, mesmo que na abordagem habermasiana seja centrado na razão comunicativa (na intersubjetividade), ainda continua a ser sustentado pela crença de que a razão é o critério principal capaz de nortear o 
discurso. Todo o processo discursivo se baseia no interesse e no reconhecimento da necessidade de se chegar ao entendimento, através do estabelecimento e da conseqüente aceitação de regras dialogais. O agir dos sujeitos se baseia exclusivamente na possibilidade e na crença de uma decisão fundamentada no esgotamento dos argumentos apresentados, sendo que seriam os mais sólidos e consistentes os que fossem aceitos por todos os membros da situação de comunicação, isto é, a decisão tem que ser consensual. Esse entendimento não se refere a um consenso antes viabilizado ou esperado, mas que seja fruto de todo um exaustivo processo comunicativo, em que todos os participantes, guiados pela busca da verdade, tenham submetido suas argumentações à apreciação dos seus interlocutores e as transformado, caso a análise racional assim demonstrasse essa necessidade.

Para que o processo ora descrito ocorra, faz-se necessária uma discussão aberta e irrestrita, pois só assim pode-se chegar à verdade, que é o objetivo da pragmática formal habermasiana. É através da pretensão de validade que a comunicação, tomada do ponto de vista intersubjetivo, é possibilitada.

Habermas (1989) propõe dois princípios reguladores da discussão, através dos quais se pode aceitar e validar os conhecimentos fundamentados nas argumentações: princípio Universalização e princípio Discurso. Ambos partem da perspectiva de que os resultados obtidos através do diálogo dizem respeito à coletividade e, portanto, devem ser acolhidos dessa maneira por seus membros. A única coação possível, para a teoria do agir comunicativo, é a pressão exercida pelo melhor argumento sobre os demais através da argumentação e da veracidade da fala.

Assim, a ação comunicativa enfatiza o entendimento através da argumentação racional, busca a liberdade, a emancipação. Siebeneichler (1989) cita um trecho de um discurso de Habermas, proferido em 1965: “(...) a humanidade, que aspira a chegar à maioridade, desenvolve-se na História através do diálogo, da comunicação” (p. 143). A crença habermasiana na maioridade, na autonomia, na libertação da humanidade, apóiase no contexto amplo de razão, contrário à razão positivista. A orientação por princípios éticos é imprescindível para que o consenso, o entendimento, seja alcançado no plano grupal e, para que esse ocorra, os sujeitos não podem mais ser guiados pela busca do prazer, por meio da obediência e da troca de favores pela via da satisfação concreta de interesses e cumprimento "cego" das leis. Os sujeitos capazes de participar de situações dialógicas, no plano psicogenético da moral, devem, antes de mais nada, ser guiados por princípios universalistas, pois só assim poderão conduzir argumentativamente suas colocações, no sentido de concordarem com uma opção mais bem fundamentada.

A teorização habermasiana é marcada por uma posição diferenciada frente aos frankfurtianos pois, ao contrário destes, a defesa do projeto do Esclarecimento possibilita a Habermas a reconstrução de um conceito de razão em um mundo desencantado, sendo, a partir da fé em uma razão universal, enfatizada em seu caráter processual sustentado na intersubjetividade que ele ratifica a racionalidade comuni- cativa muito mais como uma atitude, uma postura frente a um mundo pós-tradicional à mercê da razão instrumental e funcionalista.

Como Habermas acentua sua fé em uma razão universal, torna-se complicado o entendimento da esfera subjetiva, entendida como vivência e expressão de experiências singulares, exemplares e privadas, muitas vezes não interpretáveis de modo razoável pelo próprio sujeito, carecendo de formas de entendimento e expressão compartilháveis, permanecendo no campo da experiência. Tais experiências reivindicam franqueza, expressão, sinceridade consigo mesmo, em uma concepção da ética foucaultiana. Tal lógica de pensamento pode pôr em risco a perspectiva habermasiana de que as demandas mais efetivas postas em jogo em um discurso sejam a afirmação e a busca pela verdade e pela justiça (sendo estes os dois pilares de toda construção iluminista, nos campos da razão teórica e prática, respectivamente), pois tais peculiaridades subjetivas podem radicalizar um nível de sinceridade tal que satisfaça o sujeito, mas que não possibilite a construção de uma comunidade baseada em argumentações habilmente passíveis de contestação racional em favor do bem-estar de todos. Em lugar da sinceridade, Habermas sempre fala em autenticidade, porém não afirma que são estas as bases importantes para a efetivação do discurso, mas sim os valores da verdade e da justiça, atingíveis pelo exercício de pensamento que exige dos sujeitos construções operatório-formais, segundo Piaget, e pós-convencionais, segundo Kohlberg.

Nesse sentido, a teoria de Habermas coloca-se contra a perspectiva unilateral da razão instrumental, porém recai em forte unilateralismo ao partir de um ponto de vista racionalista, não considerando aspectos que escapam do campo da filosofia da consciência, terminando por se delinear em uma racionalidade reguladora da subjetividade. Compartilhamos com Souza (1997), acompanhando sua opinião, quando assinala que "a posição habermasiana dirige-se, antes de tudo, contra os críticos do Iluminismo e da modernidade que, no rastro de Nietzsche, percebem o ponto de partida da experiência estética como o outro da razão por excelência” (p. 140).

Latour (1994) lança questões extremamente perspicazes quanto à nossa constituição como modernos, apontando para o caráter ideológico do imaginário da modernidade e o que autoriza. O autor problematiza sobre a possibilidade de jamais termos sido, de fato, modernos, já que sempre convivemos, mesmo sem reconhecer formalmente, ‘outros’ não modernos, porém em um contínuo paradoxal de tentar purificá-los, enquadrando-os aos regimes modernos de espaço, tempo, movimento, consciência, indivíduo, natural, social..., e, nessa tentativa, termina reconhecendo-os e multiplicando-os. É como se a grande empreitada da modernidade seja lutar contra o que lhe é estranho, o não moderno, o que é um modo de se afirmar pelo que nega existência. A análise instigante de Latour acentua a pureza e a hibridação como os dois movimentos da constituição moderna, o que o leva a criticar, até ironicamente, a proposta habermasiana de retomada do ideário iluminista:

(...) é ainda pior quando tentam proteger o projeto moderno do perigo de seu desaparecimento. Habermas exprime esse 
esforço desesperado. Será que ele vai mostrar que nada nunca separou profundamente as coisas das pessoas? Será que vai retomar o projeto moderno, demonstrar os avanços da prática por sob as justificativas da Constituição? Pelo contrário, ele acredita que o perigo supremo vem da confusão entre os sujeitos falantes e pensantes com a pura racionalidade natural e técnica permitida pela antiga Filosofia da consciência! (Latour, 1994, p. 59-60).

É nessa perspectiva que as críticas às propostas habermasianas se colocam, já que, embora apontem para os desastrosos rumos do paradigma moderno, só vêem nele próprio o espaço de revitalização do ideal de emancipação do homem. A emancipação iluminista é possível somente pelo alcance da maioridade racional a todos os campos de vida humanos e não-humanos. A razão crítica é a guia e a guardiã desta tarefa, purificando todas as dificuldades que possam confundir ou dificultar o processo que visa ao aperfeiçoamento maior possível. Será que a emancipação só pode ser pensada no espaço do pensamento iluminista? Será que a razão é o único solo e o único instrumento capaz de nos possibilitar um lugar considerável perante o mundo e nós mesmos?

\section{Pluralidade descritiva e ético-pragmática}

As concepções neopragmáticas de Rorty (1994, 1995, 1996, 1997) vêm sendo, cada vez mais, presentes nas discussões acerca da Filosofia, da Ciência, da Psicologia e da Psicanálise. Essas influências começam a surtir efeito, gerando elaborações teórico-clínicas que vêm colorindo ainda mais o panorama acadêmico e editorial brasileiro, engordando as vertentes de estudo que se apóiam em críticas ferrenhas contra a Filosofia "representacionalista” que, como afirma Rorty, deve ser considerada somente como um “episódio na História da cultura européia” (1994, p. 382).

A concepção rortyana de Filosofia se constitui a partir de sua atitude terapêutica - como implacável seguidor de Wittgenstein, em relação ao modo como alguns pontos de conversação se erigem como problemas filosóficos, travestindo-se em categorias que passam a centralizar as preocupações de uma Filosofia que, prioritariamente, se debruça sobre a busca dos espaços últimos para o pensamento, através de investigações construtivas e sistemáticas. Rorty (1994) sustenta que o objetivo maior da Filosofia é o de se questionar, colocando em xeque os seus próprios princípios, ou melhor, seus fundamentos. São as noções de mente, pensamento, essência, verdade, objetivismo e realidade que são fragilizadas. É a não-preferência pela ontologia como base que marca a posição do filósofo como "terapeuta conceitual” que corresponde a "fazer o leitor questionar seus próprios motivos para filosofar do que supri-lo de um novo programa filosófico" (Costa, 1994b, p. 21), concebendo a Filosofia como o “continuar uma conversação", desfazendo os nós conceituais encarados com problemas semânticos e não como categorias doutrinarias.

Rorty (1994, p. 382), criticando as Filosofias "representacionalistas”, fundacionistas ou essencialistas, não parte do pressuposto de que entre o conhecedor e a realida- de há uma relação de correspondência. Para ele, não existe nada entre o pensador e o que pensa, sendo descartável o apelo às categorias de mente, razão, Linguagem, alma e consciência. Também passa a ser desnecessária a preocupação com a distinção entre valores, atitudes e crenças. Ele propõe uma Filosofia da atividade cuja tarefa principal seria o esclarecimento de proposições, que se sustenta na prioridade dada à noção de linguagem como ponto fundamental da concepção rortyana de sujeito. Leia-se bem: linguagem e não a Linguagem. A visão pragmática da linguagem diferencia-se da representacional, na qual conhecer é representar o mundo para algo, pessoa ou função cognitiva. Rorty (1997) assevera que "a linguagem substitui a mente como algo que supostamente se encontra sobre e em contraposição à realidade” (p. 14), referindo-se às questões do realismo e idealismo. Como ressalta Bezerra Jr. (1997), “a linguagem não é um foco de luz que ilumina a nossa abissalidade, fazendo com que enxerguemos o que antes era apenas sentido no escuro” (p. 77). É a linguagem que é enfatizada no enfoque pragmático, linguagem múltipla em seu uso, constituindo-se em jogos contextualizados nas práticas sociais, não havendo realidade extralingüística anterior ou heterogênea à linguagem.

A noção de verdade não se põe, como no “representacionalismo”, na correspondência com fatos, mas na própria linguagem e não na relação desta com as coisas. A pergunta não é como a coisa é em si, mas como a comunidade dos falantes usa tal ou qual termo para definir isso ou aquilo, fazendo com que digamos que isso é cultura, é natureza, é o inconsciente. Conhecer corresponde a lidar com os dados que perpassam a interação organismo-meio, sendo o sujeito um dos efeitos desta interação. Não sendo interno, tampouco intrínseco e estrutural, o sujeito é o nome coletivo que abrange todos os eus que um organismo é capaz de apresentar na sua história, daí poder ser descrito de várias e distintas formas, todas logicamente válidas, podendo, inclusive, o sujeito ser descrito no vocabulário do mental e do fisico.

O sujeito, então, seria o conjunto de tramas e desejos atribuídos a um organismo, o conjunto das posições subjetivas dos eus, que seriam partes dessa rede de crenças e desejos que nele opera. Para se lidar com alguém como sujeito, precisa-se atribuir a este alguém uma trama de crenças e desejos que o causem. Por enquanto, só se faz isso com relação aos humanos, porém, na história da humanidade nem sempre foi assim, por exemplo, com as crianças, com os negros, etc.

Para a Pragmática, o sujeito não é diferente do eu, ou melhor, dos eus, já que estes carregam a mesma qualidade que aquele; não há, portanto, necessidade de que uma concepção de eu seja hegemônica por pressuposições. Os vários eus correspondem a diversas crenças que se organizam de modos diferentes. Nesse sentido, o que possui relevo são os panos de fundo das crenças ou as redes de relações que sustentam tais descrições, já que qualquer uma se dá nos hábitos de linguagem ordinária, sendo as crenças, contextualmente construídas, avaliações da verdade, ou melhor, avaliações da justificação. Costa (1994a) afirma que “o sujeito é despojado de todo o suporte 'essencial', idealista 
ou realista. Nem corpo, nem conceito; nem sensível, nem inteligível; nem superficial, nem profundo, o sujeito é uma 'realidade linguística’, depende de contextos historicamente contingentes” (p. 138). Então, tanto sujeito, quanto eu e self não passam de efeitos de linguagem, entendida como conjunto de atos de fala, assim como

crenças e desejos são realidades lingüísticas. Realidades que não têm uma só definição ou uma particularidade comum à diversidade com que se apresentam na linguagem corrente. As regras de ação são seguidas conforme a tradição ou inventadas conforme os contextos de vida. Estão atreladas aos desejos, os quais, por sua vez, não são redutíveis a um só e grande desejo. Desejo, pragmaticamente definido, é tudo o que na linguagem ordinária chamamos desejo (Costa, 1994b, p. 23-24).

Rorty (1996) escreve que nesse constante processo de mudança de nossas crenças e desejos, só podemos avaliar retrospectivamente por que houve transformação no sistema de crenças e não antecipar o que tem e como tem que ser transformado, já que o postulado essencialista-introspectivo não funciona como ferramenta de exercício de si.

Bezerra Jr. (1997), enfatizando a potência performativa do vocabulário subjetivo, escreve que

uma abordagem desse tipo pode levar à conclusão de que a introspecção simplesmente não existe, por impossibilidade lógica, por inverificabilidade empírica, pelo fracasso da linguagem em descrever a 'coisa em si', ou argumentos do gênero. Mas uma conclusão como essa só se impõe quando nos afastamos da linguagem ordinária, das práticas sociais, e das regras que governam os jogos de linguagem encontrados nas forma de vida efetivamente existentes. Porque embora possamos encontrar boas razões teóricas para despachar a introspecção para o éter, quando o fazemos estamos de fato nos afastando da vida terrena, do cotidiano dos indivíduos que vivem numa cultura psicológica (p. 75).

Toda a discussão sobre o sujeito e o(s) eu(s) é bem interessante para o neo-pragmatismo por fazer saltar aos olhos as questões da pluralidade descritiva e da verdade. Não há conhecimento verdadeiro em si, uma descrição só o é caso sirva às nossas metas, funcionando em contextos particulares e, portanto, sendo discutíveis de acordo com os confrontos entre os atores históricos concretos. Os critérios de verdade são as justificações de valor pragmático de tal ou qual asserção, que a torna adequada ou não. Nesse sentido, a linguagem, sendo performativa, funciona como ferramenta, instrumento, jogo, como gramática. O que faz que se escolha esta ou aquela descrição, e que se refute outras, são critérios não-dogmáticos, mas critérios pragmáticos, nos quais a utilidade e o uso ocupam lugar primordial. A verdade se constrói pelos interesses, já que se não se tem boa resposta para alguma questão, tem-se que perguntar se é uma boa pergunta mesmo a quem a faz. Não é perguntar pela coisa intrínseca, mas pelos hábitos lingüísticos que se remetem às práticas humanas, ao que é humanamente construído e, portanto, útil.

Assim, a Neo pragmática ressalta a possibilidade de descrições plurais que ocupam o mesmo status e vários discur- sos e práticas, podendo até parecer antagônicos: são descrições do mundo instáveis, construídas, cuja escolha de uma ou de outra é ética. É nesse sentido que a defesa de um ponto de vista deixa de ser natural, para ser valorativo, de acordo com o interesse.

A questão da pluralidade descritiva e da possibilidade da co-existência de descrições antagônicas é importante como crítica ao corolário epistêmico iluminista dos dualismos, já que como a verdade não é intrínseca aos objetos e à própria Ciência, não se coloca como espelho da natureza, não há a necessidade de categorização do mundo em isto ou aquilo. Interessante é a discussão de Bezerra Jr. (1997), ao lidar com a noção de introspecção - o quanto ela é descartável pelo neopragmatismo, tecendo importantes considerações sobre a falência do dualismo interno-externo, a partir das variadas possibilidades de usos que fazemos dos termos psicológicos nos contextos de linguagem aos quais estamos habituados a nos engajar. Portanto, o neopragmatismo ergue-se, como forte crítica às perspectivas filosóficas antimetafisica, antifundacionista e antiessencialista, o que significa afirmar que surge como uma voz contra toda a tradição da Ilustração, imprimindo um olhar que prioriza a imanência, a historicidade dos juízos, valores e finitude.

Rorty (1997) questiona rigorosamente o paradigma iluminista, porém situa suas considerações, como não podia ser diferente, pelas características de seu solo filosófico pragmático, de modo distinto de alguns fortes críticos da modernidade, como Habermas e Lyotard. Em relação ao primeiro, indispõese contra a noção transcendental de linguagem que adota e contra a proposta de uma comunidade cosmopolita discursivamente mediada, advinda da participação de sujeitos morais racionalmente autônomos. Contra Lyotard, ele o questiona a partir de considerações extremamente frutíferas sobre as tradições filosóficas francesa, alemã e anglo-saxônica. Escreve que Lyotard toma como meta, para uma redescrição possível da civilização, a idéia de emancipação, idéia que consolidaria um cosmopolitismo cujas bases não estariam em grandes discursos sobre o mundo e o homem, mas que existiria espaço para as construções singulares e para a construção universal em busca de uma liberdade experimentada na vida.

Rorty (1997) escreve que

a utopia pragmática não é então, aquela em que a natureza humana tenha sido liberta, mas aquela em que todo mundo tenha tido a chance de sugerir modos através dos quais nós pudéssemos reunir rapidamente e a grosso modo uma sociedade mundial (ou galática), e na qual todas essas questões tivessem sido discutidas em encontros livres e abertos (p. 283).

Enfatiza que eles, os pragmáticos, querem

narrativas acerca de um cosmopolitismo crescente, apesar de não querermos narrativas acerca de emancipação. Pois nós pensamos que não há nada para emancipar; exatamente como não há nada que a evolução biológica tenha emancipado ao se mover dos trilobites para os antropóides (p. 283).

Rorty situa a proposta de Lyotard como "uma retórica revolucionária”, afirmando a urgência de “uma retórica refor- 
mista acerca da tolerância crescente e da sujeição decrescente” (1997, p. 137), que se efetivaria pela persuasão e não pela força. Ele insiste em ratificar que o programa cosmopolita neopragmático considera que "as Histórias universais futuras da humanidade” irão descrever os momentos culturais anuais a partir de outros vocabulários que, segundo Rorty, serão mais adequados a uma vida melhor, pragmaticamente tratando o termo: é a confiança nas possibilidades plurais de descrição e reorganização do mundo em busca de uma ética de vida e de uma vida ética!

\section{Referências}

Apel, K. O. (1994). Estudos de moral moderna. Petrópolis, Rio de Janeiro: Vozes.

Bezerra Jr., B. C. (1997). A paixão da linguagem - processos de subjetivação contemporâneos: uma leitura de Clarice Lispector. Tese de Doutorado nãopublicada, Universidade do Estado do Rio de Janeiro, Rio de Janeiro.

Costa, J. F. (1994a). A ética e o espelho da cultura. Rio de Janeiro: Rocco.

Costa, J. F. (Org.). (1994b). Redescrições da Psicanálise: ensaios pragmáticos. Rio de Janeiro: Relume-Dumará.

Freitag, B. (1990). A teoria crítica ontem e hoje. São Paulo: Brasiliense.
Freitag, B. (Org.). (1992). Habermas. São Paulo: Ática.

Habermas, J. (1989). Consciência moral e agir comunicativo. Rio de Janeiro: Tempo Brasileiro.

Latour, B. (1994). Jamais fomos modernos: ensaios de antropologia simétrica. São Paulo: Ed. 34.

Lyotard, J.-F. (1985). A condição pós-moderna. Lisboa: Gradiva.

Rorty, R. (1994). A filosofia e o espelho da natureza. Rio de Janeiro: RelumeDumará.

Rorty, R. (1995). Feminismo, ideologia e desconstrução: uma visão pragmática. In S. Zizek (Org.), Um mapa da ideologia (pp. 227-234). Rio de Janeiro: Contraponto.

Rorty, R. (1996). Cosmopolitarism without emancipation: a response to Lyotard. In S. Lash \& J. Friedman (Org.), Modernity \& identity (pp. 59-72). Cambridge: Blackwell.

Rorty, R. (1997). Objetivismo, relativismo e verdade - ensaios filosóficos I. Rio de Janeiro: Relume-Dumará.

Rouanet, S. P. (1987). As razões do Iluminismo. São Paulo: Companhia das Letras.

Rouanet, S. P. (1993). Mal-estar na atualidade. São Paulo: Companhia das Letras.

Siebeneichler, F. B. (1989). Razão comunicativa e emancipação. Rio de Janeiro: Tempo Brasileiro.

Souza, J. (1997). Patologias da modernidade - um diálogo entre Habermas e Weber. São Paulo: Annablume.

Leônia Cavalcante Teixeira é doutora em Saúde Coletiva pelo Instituto de Medicina Social da Universidade do Estado do Rio de Janeiro, mestre em Educação pela Universidade Federal do Ceará e professora da Universidade de Fortaleza (UNIFOR) nos cursos de Mestrado e Graduação em Psicologia.

Endereço para correspondência: UNIFOR - Mestrado em Psicologia, Av. Washington Soares, 1321, Édson Queiroz, Caixa Postal 1258, Fortaleza-CE, CEP 60811-341. Fone: (85) 477.3219. Fax: (85) 477.3063. Email: leoniat@unifor.br 